\title{
A[ए]
}

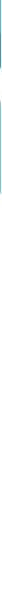

Economics Working Paper Series

Faculty of Business, Economics and Law, AUT

\section{Impact of State Children's Health Insurance Program on Fertility of Immigrant Women}

Kabir Dasgupta, Keshar Ghimire, and Alexander Plum

2020/09 


\title{
Impact of State Children's Health Insurance Program on Fertility of Immigrant Women
}

\author{
August 2020 \\ Kabir Dasgupta ${ }^{\dagger}$, Keshar Ghimire $^{\vee}$, and Alexander Plum ${ }^{+}$
}

\begin{abstract}
Between 1997 and 2000, all states in the United States (US) enacted the State Children's Health Insurance Program (SCHIP) to provide publicly funded health insurance coverage for children in low income families. However, only 15 states including the District of Columbia chose to provide coverage for children of newly arrived immigrants in their SCHIP. We exploite the resulting state and time variation in the implementation of the program in a difference-in-differences framework to estimate the effect of a publicly funded children's health insurance benefit on immigrant women's fertility. While estimates from full samples show that the net effect of the program was indistinguishable from zero, we find a significant positive effect on the fertility of unmarried immigrant women, both at extensive and at intensive margin. Our findings have important policy implications for societies experiencing a persistent decline in fertility.
\end{abstract}

Keywords: State Children's Health Insurance Program; Immigrant Fertility; Birth rate; Quantityquality tradeoff.

JEL Codes: I13; J13

\footnotetext{
${ }^{\dagger}$ Faculty of Business, Economics \& Law, Auckland University of Technology, New Zealand

$\checkmark$ Department of Economics, University of Cincinnati - Blue Ash, United States of America
}

Correspondence to: New Zealand Work Research Institute, Auckland University of Technology, Private Bag 92006, Auckland 1142, New Zealand. E-mail address: kabir.dasgupta@aut.ac.nz

Acknowledgement: We are thankful to the participants and discussants of Midwest Economic Association (2019), St. Louis USA; International Health Economics Association (2019), Basel, Switzerland; and Southern Economic Association (2019) Fort Lauderdale, USA for providing helpful comments and feedback on the analysis. We are solely responsible for all errors committed in this study. 


\section{INTRODUCTION}

This study investigates the impact of the Child Health Insurance Program (CHIP), formerly known as the State Children's Health Insurance Program (SCHIP), on immigrant women's fertility. ${ }^{1}$ The conceptual foundation underlying our analysis is the so called 'quantity-quality trade-off model' which implies that given limited resources, parents are forced to optimize their fertility decisions based on their quantity/quality preferences (Becker \& Lewis 1973; Becker \& Tomes 1976). According to the model, an increase in child quantity often requires compromising on the allocation of limited resources such as parental time and market-based goods including food, nutrition, and healthcare across offsprings. Therefore, social welfare programs that can effectively reduce parents' financial burden by extending health insurance coverage to uninsured children can arguably boost childbirth incidence ${ }^{2}$.

The CHIP is a large-scale joint initiative between the federal and state governments to provide health insurance coverage to uninsured children in low-income ('working poor') families who do not qualify for Medicaid. ${ }^{3}$ Although eligibility criteria in the benefit program may vary across states, in general the program extends enrolment among children whose family income lies above the Medicaid eligibility but lower than $200 \%$ of Federal poverty level (Edmunds et al. 1998). Enacted into law as a part of the Balanced Budget Act in 1997, implementation of CHIP across states prompted a drop in child uninsured rate from 14\% to 7\% (Paradise 2014). As CHIP reduces out-of-pocket child healthcare expenses for low-income groups, the welfare program can be expected to lower marginal cost of having a child thereby influencing fertility decisions. ${ }^{4}$

The Personal Responsibility and Work Opportunity Reconciliation Act (PRWORA) of 1996 prohibited all non-naturalized newly arrived immigrants from receiving any federal means-tested benefits including the Medicaid. ${ }^{5}$ However, utilizing state autonomy afforded by the Balanced Budget Act, 15 states including Washington DC ('generous' states) included children of newly arrived immigrants in their CHIP. ${ }^{6}$ Newly arrived non-naturalized immigrants in other 'non-generous' states remained ineligible for CHIP coverage. We exploit this variation in immigrant eligibility for CHIP benefits across states as a 'natural experiment' in a difference-in-differences (DD) framework to estimate the effect of child health care benefit on fertility. Although our current analysis focuses on immigrant women, our findings suggest the need for additional research to see if similar benefits targeted at children can be effective at enhancing fertility at least among some population groups.

\footnotetext{
1 Our focus on immigrant population is motivated by a policy variation, described later, that affords relatively straightforward causal identification in this group.

${ }^{2}$ See Doiron and Kettlewell (2020) for latest evidence on how fertility decisions are associated with demand for health insurance.

${ }^{3}$ Medicaid provides health insurance coverage to low income families. This program is not specifically targeted to children.

${ }^{4}$ We explain the potential underlying mechanisms using a standard quantity-quality tradeoff model in Appendix Section A.1.

${ }^{5}$ Prohibition lasted for five years after entering as an immigrant. Certain categories such as refugees were exempted from the restriction.

${ }^{6}$ We provide state-specific years of implementation and relevant classification by generosity in Appendix Table A.1.
} 


\section{METHODS}

\subsection{Prior evidence}

There is ample evidence that social welfare interventions such as parental leave, income tax credits, and childcare support that are effective in reducing parental resource constraints can positively influence childbearing decisions (Lalive \& Zweimuller, 2009; Azmat \& González 2010; Haan \& Wrohlich, 2011; Brewer \& Ratcliffe, 2012). However, majority of the studies in this space draw from the experiences of European economies that are also characterized by generous public benefits on several other fronts not directly related to child care costs (Walker, 1995; Ronsen, 2004; Duvander \& Andersson, 2006; Gauthier, 2007). The relatively scant US-based evidence pertinent to our analysis includes evidence on the beneficial impacts of means-tested benefit programs like Medicaid on prenatal care and birth outcomes (Ray et al., 1997; Baldwin et al., 1998). Most closely related to our study is a paper by Zavodny \& Bitler (2010) who explore the effects of Medicaid eligibility expansions on fertility. The authors find that, on average, the eligibility-based intervention did not affect overall birth rates but did boost fertility in a small subset of white women without a high school degree.

\subsection{Data and Model}

We utilize the data from Annual Social and Economic Supplement of the Current Population Survey (CPS) for the years 1997 through $2009 .{ }^{7}$ The outcome variable in our analysis is a binary indicator denoting whether an immigrant woman gave birth to a new child during a given year. The key explanatory variable is the availability of generous CHIP in the respective state and year. Covariates include age, race, ethnicity, marital status, education, number of other children and indicator for having a child younger than five. State level covariates include state unemployment rate as a proxy for economic conditions in the state and an indicator for whether governor is democrat as a proxy for political/social conditions in the state. The descriptive information of all the variables used in our analysis is summarized in Table $1 .^{8}$

We analyze fertility decisions of immigrant women of childbearing ages (15-45). ${ }^{9}$ First, we look at the effect of generous CHIP implementation on childbearing of an overall sample of immigrant women and then we classify the samples by their marital status. For each sample, we estimate the DD model

$$
Y_{i s t}=\beta_{1}+\beta_{2} \cdot C H I P_{s t}+X_{i s t} \cdot \beta_{3}+Z_{s t} \cdot \beta_{4}+\eta_{s}+\lambda_{t}+\phi_{s} \cdot t+\epsilon_{i s t}
$$

where $Y_{\text {ist }}$ is a binary indicator of childbirth of an immigrant woman $i$ in state $s$ and the year $t$. CHI $P_{s t}$ indicates whether the state $s$ in year $t$ has a generous CHIP in place. The parameter $\beta_{2}$ represents the estimate of the impact of generous CHIP on childbearing among immigrant women. To account for endogeneity arising from exclusion of relevant covariates, we control for a range of individual-and state-level characteristics $\left(X_{\text {ist }}\right.$ and $\left.Z_{s t}\right)$, state $\left(\eta_{s}\right)$ and year $\left(\lambda_{t}\right)$ fixed effects, and state-specific linear time trends $\left(\phi_{s} . t\right)$. In addition to the DD regressions, we conduct an event analysis, described later in the manuscript, as a test for parallel trends assumption necessary for DD analysis.

As an important supplement to our baseline analysis, we also employ a difference-in-difference-indifferences (DDD) model that estimates change in fertility of immigrant women in generous states net

\footnotetext{
${ }^{7}$ Due to the introduction of substantial welfare reforms by the PRWORA, the pre-1997 era represents a distinct welfare regime. Furthermore, in 2009 the CHIP Reauthorization Act (CHIPRA) allowed all states to cover all immigrant children with federal funds, irrespective of when they entered the country.

${ }^{8}$ We present summary stats on a combined sample of women including immigrants and natives for comparison purposes.

${ }^{9}$ For robustness check, we also analyze a smaller sample of women aged 17-40 where most births are concentrated. See Figure A.1.
} 
of changes in fertility of immigrant women in non-generous states as well as net of changes in fertility of non-immigrants who do not stand to be affected by generous CHIP. The triple difference model takes the form

$$
\begin{aligned}
& Y_{i s t}=\delta_{1}+\delta_{2} \cdot \text { Immi }_{i} \cdot \text { Generous }_{s} \cdot \text { Post }_{s t}+\delta_{3} \cdot \text { Immi }_{i} \cdot \text { Generous }_{s}+\delta_{4} \cdot \text { Immi }_{i} \cdot \text { Post }_{\text {st }} \\
&+\delta_{5} . \text { Generous }_{s} . \text { Post }_{s t}+\delta_{6} \cdot \text { Immi }_{i}+\delta_{7} \cdot \text { Generous }_{s}+\delta_{8} . \text { Post }_{s t}+X_{i s t} \cdot \delta_{9} \\
&+Z_{s t} \cdot \delta_{10}+\eta_{s}+\lambda_{t}+\phi_{s} \cdot t+v_{i s t}
\end{aligned}
$$

where, $\operatorname{Immi}_{i}$ is the indicator of whether woman $i$ is an immigrant; Generous is an indicator of whether state $s$ covers immigrant population in its CHIP; and Post st $_{\text {in }}$ equals 1 to represent post-CHIP implementation years for state $s$. The parameter $\delta_{2}$ represents the DDD estimate of the impact of the policy of our interest in fertility of immigrants. The triple difference estimator ensures that we are accounting for any unobserved changes that may differentially affect fertility in generous and nongenerous states.

\section{RESULTS}

Our main results from estimating Equation 1 are presented in Table 2. We analyze three sample types: all immigrant women, married immigrant women, and unmarried immigrant women. ${ }^{10}$ Consistent with Zavodny \& Bitler's (2010), the weighted linear probability model (LPM) estimates indicate that CHIP did not have any statistically significant impact on the overall immigrant population. The estimates of the effect of CHIP on fertility of married immigrant women is also in line with the full sample results and shows no effect distinguishable from zero. However, the program appears to have a significant positive impact on women who are not in a married relationship. Importantly, this group has the lowest average family income and health insurance coverage rate (see Table 1). For unmarried immigrant women aged 15-45, CHIP implementation in generous states is followed by a 1.8 percentage point increase in the probability of having a childbirth (see Table 2, Panel A). The coefficient is statistically significant at 1\% level. Results from the 17-40 age group, presented in Panel B are not too different. It is reassuring to see that the results from the triple difference (DDD) model shown in Panel C are also qualitatively similar to those obtained from our DD model.

As a suggestive test for parallel trends assumption, we examine the effect of CHIP on immigrant fertility with an event study analysis. With data coded from -3 to +10 years from CHIP implementation, and -3 as the omitted category, we do not find any statistically significant leads in our event analysis. ${ }^{11}$ Results are graphically presented in Figure 1. In line with the DD results, the lags suggest no post CHIP swings in fertility in case of combined and married sample but an upward swing in fertility of unmarried sample.

Next we conduct a series of robustness checks. First, we estimate the effects of CHIP on immigrants at the intensive margin by investigating childbirth outcomes of women with at least one additional biological child. Second, we test the effect of CHIP on fertility of women who lie below $150 \%$ of the federal poverty threshold. And third, to account for self-selection bias that may arise from immigrant women migrating to generous states, we conduct a robustness check by limiting our sample to females who did not relocate to another state in the year prior to survey. Results from all of these checks are presented in Table 3 and do not depart heavily from our main results.

\footnotetext{
${ }^{10}$ In unreported analyses, we test for the effect of CHIP on fertility of a combined sample of immigrant and native women in the US and do not find any statistically significant effect of the program. Results are available upon request.

${ }^{11}$ Further details on event study analysis available on request.
} 


\section{CONCLUSION}

Since 2007, the total fertility rate has been declining in the US. Globally, low fertility combined with increasing life expectancy has resulted in rapidly ageing population across several major economies. This ageing phenomena can have significant long-term macroeconomic implications such as labor shortages, fiscal burden, and reduced innovations. Our study provides important insights into the understanding of whether financial safety net provided by social welfare programs that can reduce cost of raising a child influence individuals' childbearing decision. In large combined samples, we do not find any impact of CHIP on fertility. However, consistent with the quantity-quality tradeoff model, we do find a significant rise in childbirth incidence among a subpopulation of immigrant women who are likely to belong to a socio-economically vulnerable group. Our findings suggest the need for further research to explore the specific mechanisms behind these results and assess the extent to which these findings can be generalized to other population groups. 


\section{REFERENCES}

- Azmat, G., \& González, L. (2010). Targeting fertility and female participation through the income tax. Labour economics, 17(3), 487-502.

- Baldwin, L. M., Larson, E. H., Connell, F. A., Nordlund, D., Cain, K. C., Cawthon, M. L., ... \& Rosenblatt, R. A. (1998). The effect of expanding Medicaid prenatal services on birth outcomes. American Journal of Public Health, 88(11), 1623-1629.

- Becker, G. S., \& Lewis, H. G. (1973). On the Interaction between the Quantity and Quality of Children. Journal of Political Economy, 81(2, Part 2), S279-S288.

- Becker, G. S., \& Tomes, N. (1976). Child endowments and the quantity and quality of children. Journal of Political Economy, 84(4, Part 2), S143-S162.

- Brewer, M., \& Ratcliffe, A. (2012). Does welfare reform affect fertility? Evidence from the UK. Journal of Population Economics, 25(1), 245-266.

- Doiron, D., \& Kettlewell, N. (2020). Family formation and the demand for health insurance. Health Economics, 29(4), 523-533.

- Duvander, A. Z., \& Andersson, G. (2006). Gender equality and fertility in Sweden: A study on the impact of the father's uptake of parental leave on continued childbearing. Marriage \& Family Review, $39(1-2), 121-142$.

- Edmunds, M., Coye, M. J., \& National Research Council. (1998). Overview of the State Children's Health Insurance Program. In Systems of Accountability: Implementing Children's Health Insurance Programs. National Academies Press (US).

- Gauthier, A. H. (2007). The impact of family policies on fertility in industrialized countries: a review of the literature. Population research and policy review, 26(3), 323-346.

- Ghimire, K.M., 2018. Impact of children's health insurance benefit on labor supply of adults: evidence from newly arrived immigrants. Economics Bulletin, 38(1),234-247.

- Haan, P., \& Wrohlich, K. (2011). Can child care policy encourage employment and fertility?: Evidence from a structural model. Labour Economics, 18(4), 498-512.

- Lalive, R., \& Zweimüller, J. (2009). How does parental leave affect fertility and return to work? Evidence from two natural experiments. The Quarterly Journal of Economics, 124(3), 1363-1402.

- Millimet, D. L., \& Wang, L. (2011). Is the quantity-quality trade-off a trade-off for all, none, or some? Economic Development and Cultural Change, 60(1), 155-195.

- Paradise, J. (2014). The Impact of the Children's Health Insurance Program (CHIP): What Does the Research Tell Us? Kaiser Family Foundation (July 2014), available at http://kff. org/medicaid/issue-brief/the-impact-of-the-childrens-health-insurance-programchip-what-doesthe-research-tell-us.

- Ray, W. A., Mitchel, E. F., \& Piper, J. M. (1997). Effect of Medicaid expansions on preterm birth. American Journal of Preventive Medicine, 13(4), 292-297. 
- Rønsen, M. (2004). Fertility and public policies-Evidence from Norway and Finland. Demographic Research, 10, 143-170.

- Rosenbach, M., Ellwood, M., Czajka, J., Irvin, C., Coupe, W., \& Quinn, B. (2001). Implementation of the State Children's Health Insurance Program: Momentum Is Increasing after a Modest Start. First Annual Report.

- Schultz, T. P. (1994). Marital status and fertility in the United States: Welfare and labor market effects. Journal of Human Resources, 637-669.

- Walker, J. R. (1995). The effect of public policies on recent Swedish fertility behavior. Journal of Population Economics, 8(3), 223-251.

- Zavodny, M., \& Bitler, M. P. (2010). The effect of Medicaid eligibility expansions on fertility. Social Science \& Medicine, 71(5), 918-924. 
Table 1

Summary statistics

\begin{tabular}{lcccccc}
\hline \hline & \multicolumn{2}{c}{ All women (native and immigrant) } & \multicolumn{3}{c}{ Immigrant women } \\
\hline & Overall & Married & Unmarried & Overall & Married & Unmarried \\
\hline Gave birth to a new child & 0.056 & 0.084 & 0.028 & 0.068 & 0.090 & 0.033 \\
SCHIP & 0.890 & 0.887 & 0.892 & 0.895 & 0.897 & 0.891 \\
Generous SCHIP & 0.388 & 0.375 & 0.401 & 0.550 & 0.539 & 0.569 \\
Unemployment rate & 5.278 & 5.236 & 5.317 & 5.509 & 5.505 & 5.516 \\
Democrat governor & 0.442 & 0.437 & 0.446 & 0.423 & 0.423 & 0.423 \\
Lower than HS & 0.210 & 0.098 & 0.318 & 0.312 & 0.284 & 0.357 \\
HS graduate & 0.278 & 0.300 & 0.256 & 0.267 & 0.278 & 0.249 \\
Some college & 0.204 & 0.184 & 0.222 & 0.134 & 0.110 & 0.173 \\
Associate degree & 0.085 & 0.110 & 0.060 & 0.060 & 0.064 & 0.053 \\
Bachelor & 0.165 & 0.222 & 0.110 & 0.157 & 0.180 & 0.121 \\
Employed & 0.720 & 0.754 & 0.687 & 0.625 & 0.607 & 0.654 \\
Any health insurance coverage & 0.824 & 0.862 & 0.788 & 0.661 & 0.690 & 0.614 \\
Medicaid coverage & 0.112 & 0.055 & 0.167 & 0.103 & 0.074 & 0.152 \\
Age & 30.641 & 35.177 & 26.282 & 31.984 & 34.364 & 28.143 \\
White & 0.803 & 0.859 & 0.749 & 0.684 & 0.698 & 0.663 \\
African American & 0.119 & 0.065 & 0.171 & 0.080 & 0.058 & 0.116 \\
Native & 0.015 & 0.011 & 0.019 & 0.008 & 0.008 & 0.009 \\
Asian & 0.046 & 0.052 & 0.041 & 0.212 & 0.223 & 0.194 \\
Hispanic & 0.169 & 0.169 & 0.169 & 0.530 & 0.529 & 0.531 \\
Married & 0.490 & & & 0.617 & & 3.969 \\
Family income (annual) & 64929.400 & $78,936.360$ & $51,471.620$ & $55,283.840$ & $63,906.120$ & $41,366.210$ \\
Number of own children & 1.153 & 1.753 & 0.577 & 1.381 & 1.812 & 0.686 \\
Number of own child aged $<5$ & 0.313 & 0.480 & 0.153 & 0.388 & 0.519 & 0.177 \\
Immigrant & 0.155 & 0.195 & 0.116 & & & 33088 \\
\hline Sample & 558858 & 273841 & 285017 & 86497 & 53409 & \\
\hline
\end{tabular}

Notes: Data include women aged 15-45 from Annual Social and Economic Supplement of the Current Population Survey 1997-2009. The measure for annual family income is adjusted for inflation using 2005 as the reference base year. 
Table 2

Effects of Generous CHIP on immigrant women's fertility

\begin{tabular}{lccc}
\hline Panel A: Ages 15-45 & All women & Married & Not married \\
\hline Generous CHIP & $(1)$ & $(2)$ & $(3)$ \\
& -0.004 & -0.017 & $0.018^{* * *}$ \\
& $(0.007)$ & $(0.011)$ & $(0.006)$ \\
\hline Observations & & & \\
\hline Panel B: Ages 17-40 & & & \\
\hline Generous CHIP & -0.004 & -0.021 & $0.024^{* * *}$ \\
& $(0.009)$ & $(0.013)$ & $(0.006)$ \\
& & & \\
\hline Observations & 68,122 & 41,879 & 26,243 \\
\hline Panel C: Triple difference model (ages $\mathbf{1 5 - 4 5 )}$ & \\
\hline Generous CHIP & -0.002 & -0.017 & $0.019^{* * *}$ \\
& $(0.008)$ & $(0.011)$ & $(0.006)$ \\
\hline Observations & & 2858,017 \\
\hline
\end{tabular}

Notes: All models control for personal characteristics, state characteristics, state-specific linear time trends, year fixed effects (state FE), and state fixed effects (Year FE). All the LPM regressions are weighted by ASEC sample weights. Standard errors are clustered at the state level and are reported in parentheses. $* * *, * * *=$ statistically different from zero at the $1 \%, 5 \%, 10 \%$ level. 
Figure 1

Dynamic effects of Generous CHIP implementation on immigrant women's fertility
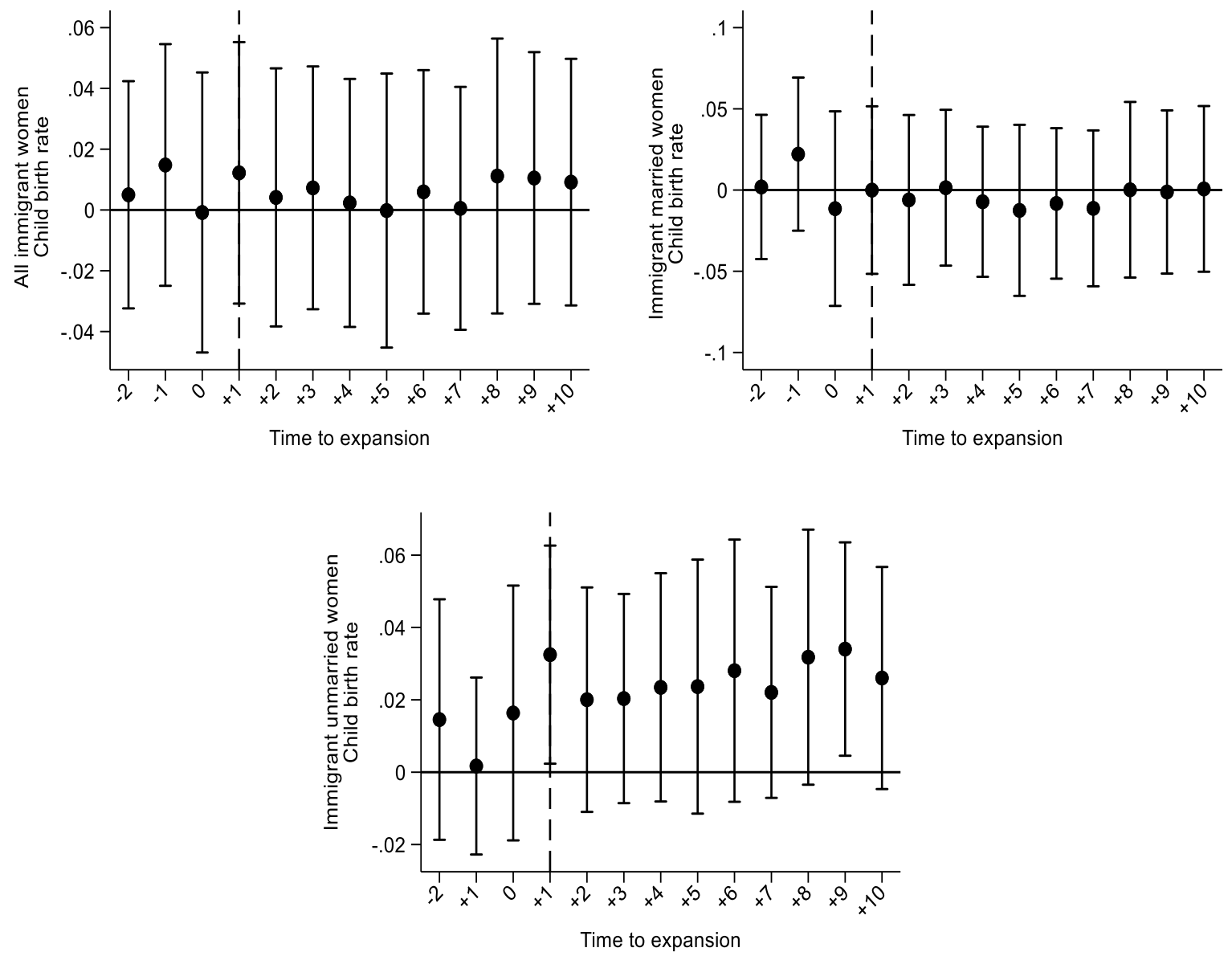

Notes: The period representing 3-year prior CHIP implementation is treated as the omitted category. 
Table 3

Robustness checks on subsamples of immigrant women

\begin{tabular}{|c|c|c|c|c|c|c|}
\hline & \multicolumn{2}{|c|}{ Same state residents } & \multicolumn{2}{|c|}{ Women with child } & \multicolumn{2}{|c|}{$<150 \%$ poverty threshold } \\
\hline & $\begin{array}{c}\text { DD } \\
\text { estimates }\end{array}$ & $\begin{array}{c}\text { DDD } \\
\text { estimates }\end{array}$ & $\begin{array}{c}\text { DD } \\
\text { estimates }\end{array}$ & $\begin{array}{c}\text { DDD } \\
\text { estimates }\end{array}$ & $\begin{array}{c}\text { DD } \\
\text { estimates }\end{array}$ & $\begin{array}{c}\text { DDD } \\
\text { estimates }\end{array}$ \\
\hline & $(1)$ & $(2)$ & (3) & (4) & $(5)$ & $(6)$ \\
\hline \multicolumn{7}{|c|}{ Panel A: All immigrant women } \\
\hline \multirow[t]{2}{*}{ Generous SCHIP } & -0.004 & -0.002 & 0.002 & -0.003 & 0.007 & 0.008 \\
\hline & $(0.008)$ & $(0.008)$ & $(0.012)$ & $(0.012)$ & $(0.015)$ & $(0.014)$ \\
\hline Observations & 81,831 & 539,107 & 38,376 & 209,938 & 29,264 & 129,567 \\
\hline \multicolumn{7}{|c|}{ Panel B: Immigrant married women } \\
\hline \multirow[t]{2}{*}{ Generous SCHIP } & -0.015 & -0.015 & -0.012 & -0.017 & -0.015 & -0.011 \\
\hline & $(0.012)$ & $(0.013)$ & $(0.014)$ & $(0.013)$ & $(0.025)$ & $(0.023)$ \\
\hline Observations & 50,790 & 264,802 & 31,637 & 162,001 & 14,982 & 37,970 \\
\hline \multicolumn{7}{|c|}{ Panel C: Immigrant not married women } \\
\hline \multirow[t]{2}{*}{ Generous SCHIP } & $0.016^{* *}$ & $0.018^{* * *}$ & $0.068^{* * *}$ & $0.061^{* * *}$ & $0.029^{* * *}$ & $0.027^{* * *}$ \\
\hline & $(0.007)$ & $(0.006)$ & $(0.021)$ & $(0.018)$ & $(0.009)$ & $(0.009)$ \\
\hline Observations & 31,041 & 274,305 & 6,739 & 47,937 & 14,282 & 91,597 \\
\hline
\end{tabular}

Notes: All models control for personal characteristics, state characteristics, state-specific linear time trends, year fixed effects (state FE), and state fixed effects (Year FE). All the LPM regressions are weighted by ASEC sample weights. Standard errors are clustered at the state level and are reported in parentheses. $* * *, * *, *=$ statistically different from zero at the $1 \%, 5 \%, 10 \%$ level. 


\section{A.1 Theoretical framework}

\section{APPENDIX}

We begin with Millimet \& Wang's (2011) utility maximization problem, which is a modified version of Becker \& Tomes' (1976) quantity-quality trade-off model. One of the important features of Millimet \& Wang's (2011) model is that the authors consider health-related resources and health endowment as inputs of child quality. Households' objective is to maximize their utility $U$ given by the function $U=U(n, q, c)$, where $n$ represents child quantity, $q$ represents child quality, and $c$ is consumption. Further, $q$ is a function of market-based health inputs $w$ and child's health endowment $\theta$. In particular, child quality is represented by the production function: $q=q(w, \theta)$, where $q$ is positively related to both $w$ and $\theta\left(q_{w}>0\right.$ and $\left.q_{\theta}>0\right)$.

Households maximize their utility subject to a budget constraint given by:

$$
\text { c. } p_{c}+n \cdot p_{n}+w n \cdot p_{w}=M \quad(A .1)^{12}
$$

, where $M$ denotes household income, $p_{c}$ is the unit price of consumption, $p_{n}$ is the cost per child, and $p_{w}$ represents price of market-purchased health inputs. In presence of economic support provided by the CHIP, equation A.1 can be modified to:

$$
\text { c. } p_{c}+n \cdot p_{n}+w n \cdot\left(p_{w}-p_{\text {chip }}\right)=M
$$

where $p_{\text {chip }}$ represents state-sponsored healthcare support for each unit of health input purchased. The equilibrium condition for the constrained utility maximization problem is given by:

$$
\begin{gathered}
\frac{\partial U}{\partial c}=\lambda p_{c}=\lambda \pi_{c} \quad(A .3) \\
\frac{\partial U}{\partial q}=\lambda \frac{\left(p_{w}-p_{\text {chip }}\right)}{\partial q / \partial w} n=\lambda \pi_{q} \\
\frac{\partial U}{\partial n}=\lambda\left(w p_{w}-w p_{\text {chip }}+p_{n}\right)=\lambda \pi_{n}
\end{gathered}
$$

In the above equations, $\pi_{c}, \pi_{q}$ and $\pi_{n}$ are the shadow prices of consumption, child quality, and child quantity, respectively. The equilibrium conditions suggest that while an unplanned or exogenous increase in number of children increases the shadow price of child quality, a statesponsored child health insurance represented by $p_{\text {chip }}$ is negatively related with the same. More specifically, ceteris paribus, CHIP coverage can reduce the cost for parents to improve child health quality if they decide to have additional child.

12 Millimet \& Wang (2011) also include children's sex ratio in their model assuming that having more children belonging to the same sex can be provide certain cost advantages to households. 
Table A.1 -CHIP implementation and immigrant coverage by state

\begin{tabular}{|c|c|c|}
\hline States & $\begin{array}{c}\text { Date of } \\
\text { implementation }\end{array}$ & $\begin{array}{c}\text { Coverage for } \\
\text { immigrants }\end{array}$ \\
\hline Alaska (AK) & March 1999 & Yes \\
\hline Alabama (AL) & February 1998 & No \\
\hline Arkansas (AR) & October 1998 & No \\
\hline Arizona (AZ) & October 1997 & No \\
\hline California (CA) & July 1998 & Yes \\
\hline Colorado (CO) & April 1998 & No \\
\hline Connecticut (CT) & October 1997 & No \\
\hline District of Columbia (DC) & September 1997 & Yes \\
\hline Delaware (DE) & October 1998 & Yes \\
\hline Florida (FL) & April 1998 & No \\
\hline Georgia (GA) & September 1998 & No \\
\hline Hawaii (HI) & January 2000 & Yes \\
\hline Iowa (IA) & July 1998 & No \\
\hline Idaho (ID) & October 1997 & No \\
\hline Illinois (IL) & January 1998 & Yes \\
\hline Indiana (IN) & October 1997 & No \\
\hline Kansas (KS) & July 1998 & No \\
\hline Kentucky (KY) & July 1998 & No \\
\hline Louisiana (LA) & November 1998 & No \\
\hline Massachusetts (MA) & October 1997 & Yes \\
\hline Maryland (MD) & July 1998 & No \\
\hline Maine (ME) & July 1998 & No \\
\hline Michigan (MI) & May 1998 & No \\
\hline Minnesota (MN) & September 1998 & Yes \\
\hline Missouri (MO) & October 1997 & No \\
\hline Mississippi (MS) & July 1998 & No \\
\hline Montana (MT) & January 1998 & No \\
\hline North Carolina (NC) & October 1998 & No \\
\hline North Dakota (ND) & October 1998 & No \\
\hline Nebraska (NE) & May 1998 & Yes \\
\hline New Hampshire (NH) & May 1998 & No \\
\hline New Jersey (NJ) & February 1998 & Yes \\
\hline New Mexico (NM) & May 1998 & Yes \\
\hline Nevada (NV) & October 1998 & No \\
\hline New York (NY) & April 1998 & Yes \\
\hline Ohio $(\mathrm{OH})$ & January 1998 & No \\
\hline Oklahoma (OK) & December 1997 & No \\
\hline Oregon (OR) & July 1998 & No \\
\hline Pennsylvania (PA) & June 1998 & Yes \\
\hline Rhode Island (RI) & October 1997 & No \\
\hline South Carolina (SC) & October 1997 & No \\
\hline South Dakota (SD) & July 1998 & No \\
\hline Tenessee (TN) & October 1997 & No \\
\hline Texas (TX) & July 1998 & No \\
\hline Utah (UT) & August 1998 & No \\
\hline Virginia (VA) & October 1998 & Yes \\
\hline Vermont (VT) & October 1998 & No \\
\hline Washington (WA) & January 2000 & Yes \\
\hline Wisconsin (WI) & April 1999 & No \\
\hline West Virginia (WV) & July 1998 & No \\
\hline Wyoming (WY) & April 1999 & No \\
\hline
\end{tabular}

Source: Rosenbach et al., 2001 and Ghimire (2018). The information on coverage for new immigrants pertains to years prior to 2009 . 
Figure A.1 - Distribution of birth across ages of women
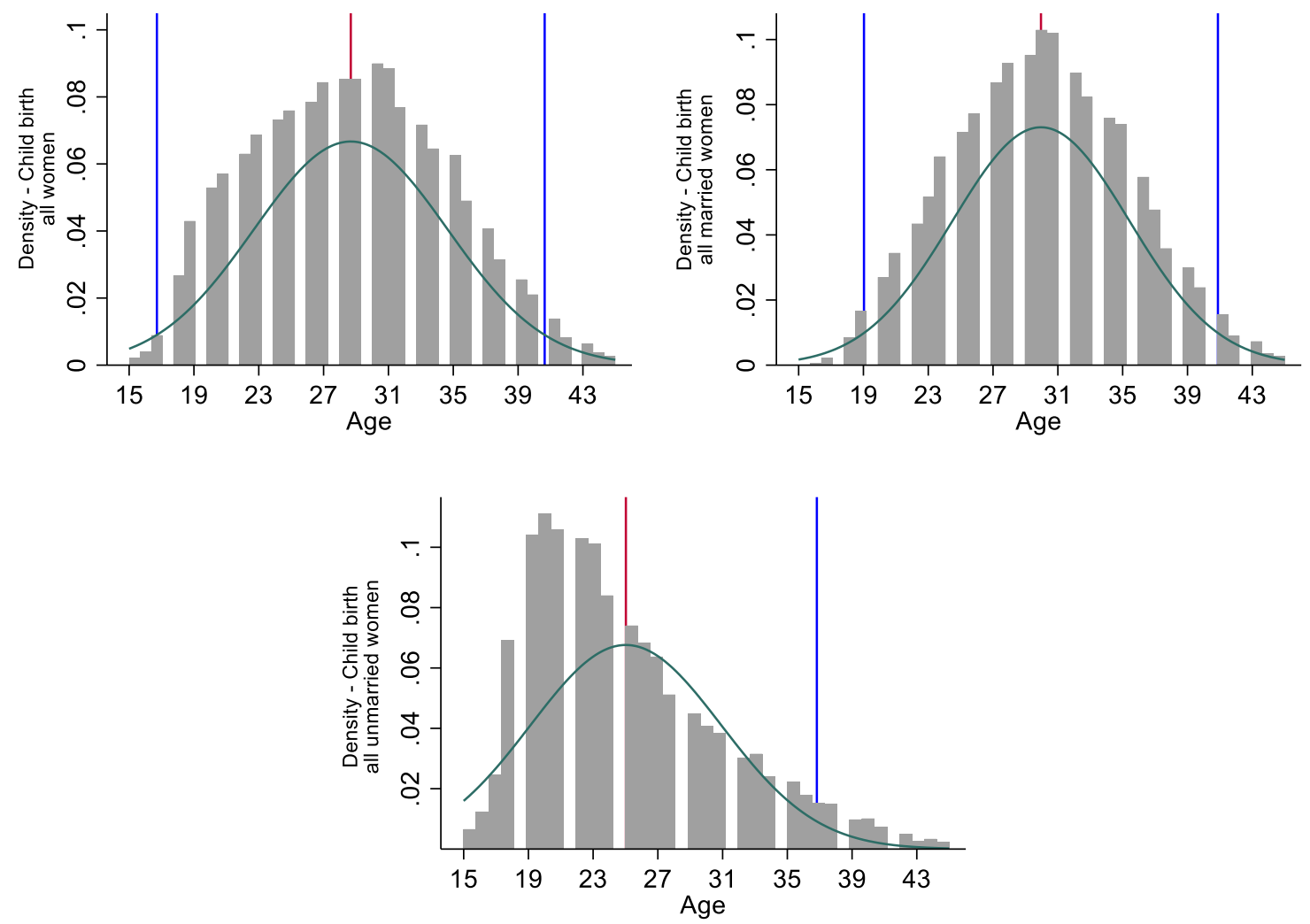